\title{
Galectin-3 induces cell migration via a calcium-sensitive MAPK/ ERK1/2 pathway
}

\author{
Xiaoge Gao ${ }^{1,2, *}$, Vitaly Balan ${ }^{1,3, *}$, Guihua Tai ${ }^{2}$, Avraham Raz ${ }^{1}$ \\ ${ }^{1}$ Department of Oncology, Karmanos Cancer Institute, Wayne State University, Detroit, MI, USA \\ ${ }^{2}$ School of Life Sciences, Northeast Normal University, Changchun, PR China \\ ${ }^{3}$ Present address: Everon Biosciences, Buffalo, NY \\ * These authors contributed equally to the work \\ Correspondence to: Avraham Raz, email: raza@karmanos.org \\ Keywords: galectin-3, calcium ions, protein kinase C, extracellular signal regulated protein kinase 1/2, cell migration \\ Received: January 15, $2014 \quad$ Accepted:February 17, 2014 Published: February 19, 2014
}

This is an open-access article distributed under the terms of the Creative Commons Attribution License, which permits unrestricted use, distribution, and reproduction in any medium, provided the original author and source are credited.

\section{ABSTRACT:}

The presence and level of circulating galectin-3 (Gal-3), a member of the galectin family, is associated with diverse diseases ranging from heart failure, immune disorders to cancer metastasis and serves as a biomarker of diagnosis and treatment response. However, the mechanisms by which exogenous Gal-3 affects pathobiology events remain elusive. In the current study, we found that exogenous Gal-3 slightly delays, while prolonging tyrosine phosphorylation of extracellular signal-regulated kinase 1/2 (ERK1/2) in HeLa cells through a calcium-sensitive and PKC-dependent signaling pathway. The activation was dependent on the sugar-binding properties of Gal-3, since the antagonist lactose could inhibit it. The sugar-binding motif of Gal-3 was required for the activation of ERK1/2. The activation of ERK1/2 was necessary for the initiation and induction of cell migration associated with the phosphorylation of paxillin. All the results presented in this study suggest a novel calcium-sensitive and PKC-dependent pathway through which circulating Gal-3 promotes cell migration and activating the ERK1/2. Taken together, the data depicted here propose a biological function and a target for the diseases' associated circulating Gal-3.

\section{INTRODUCTION}

Gal-3 belongs to the animal galectin family, characterized by specific recognition and binding of $\beta$-galactosides [1]. Gal-3 is the only chimeric protein in the galectin family based on its special structure. In addition to the evolutionarily conserved carbohydraterecognition domain (CRD), it also has the N-terminal domain composed of a short N-terminal leader and a collagen-like internal repeating domain rich in glycine, tyrosine, and proline [2,3]. Gal-3 can be found in cytoplasm and nucleus, and it can also be secreted through non-classical pathways [4,5]. Many ligands of Gal-3 have been identified, including the glycoproteins from extracellular and intracellular proteins as well as glycolipids [6]. While some binding interactions rely on the carbohydrate-binding domain of Gal-3, many Gal-3 binding partners depend on N-terminal protein-protein interaction. In the intracellular compartment, there are also many ligands, which bind mainly with Gal-3 through protein-protein interaction [7]. Gal-3 is involved in multiple biological activities dependent on its wide distribution and abundant ligands, such as cell growth, cell differention, cell apoptosis, pre-mRNA splicing, cell adhesion, cell migration, angiogenesis, chemo attraction, immune activities and so on $[8,9]$. Many researchers have reported overexpression of Gal-3 in different cancers [10, 11]. Gal-3 in tumor cells can promote growth and protect the cells from apoptosis induced by chemotherapeutic drugs $[11,12]$.

Gal-3 overexpression in cancer cells results in its higher secretion and concentration in the circulation of cancer patients [12-19]. Increased levels of serum Gal-3 is not limited to cancer as it has been associated with other diseases such as systemic lupus erythematosus, rheumatoid arthritis, Alzheimer's disease and Behçet's disease [15- 
17]. Circulating Gal-3 was positively associated with the type 2 diabetes, which could be reduced by anti-diabetes metformin [19]. It was shown, that Gal-3 was associated with fibrosis and inflammation, which has been implicated in development and progression of heart failure (HF) and predicts increased mortality and morbidity in this condition [18]. In immune cells, exogenous Gal-3 could induce apoptosis through binding with the CD29/CD7 complex, which was helpful for the immune escape of cancer cells [19].

Extracellular Gal-3 could modulate adhesion of cells to the extracellular matrix, increase tumor cell homotypic aggregation, heterotypic aggregation between tumor cells with blood vascular endothelium and induce angiogenesis in vivo and in vitro through binding with the corresponding receptors on the cell surface, which are all vital steps in the progression of cancer cell metastasis [1, 8, 9, 20]. In addition, after association with the epithelial, macrophages and endothelial cells, Gal-3 could be engulfed into the endosomes [21-23].

Here we would like to clarify the functions and associated mechanisms of circulating Gal-3 on the cell's signal transduction, and report that exogenous Gal-3 selectively activated ERK1/2, but not AKT in a calcium-sensitive and PKC-dependent manner, and the phosphorylation of ERK1/2 was necessary for cell migration. In addition we demonstrated that phosphorylation of paxillin, that was induced by activated ERK1/2 may also be involved in cell migration. These findings were meaningful for probing into exogenous Gal3 functional mechanisms and finding the potential therapy targets.

\section{RESULTS}

\section{Exogenous Gal-3 activates MAPK/ERK1/2 but not AKT in a time- and dose-dependent manner}

As reported previously, EGF (100 ng/ml) increases phosphorylation of ERK $1 / 2$ and AKT in $5 \mathrm{~min}$ and returns to a basal level after $1 \mathrm{~h}$ [24], while total ERK level did not change (Figure 1A). Compared to EGF, exogenous Gal-3 induced the phosphorylation of ERK $1 / 2$ in a delayed but prolonged way (from $15 \mathrm{~min}$ to $120 \mathrm{~min}$ ); meanwhile, Gal-3 did not induce the phosphorylation of AKT at the corresponding time. The total ERK and AKT also did not change after the treatment with Gal-3 (Figure 1B). The phosphorylation of ERK1/2 induced by EGF and Gal-3 were both aborted by U0126, the specific inhibitor of MEK1/2, suggesting that the signal was transferred through a specific Raf-MEK1/2-ERK1/2 pathway to activate ERK1/2. The phosphorylation of ERK1/2 was concentration-dependent. As shown in figure $1 \mathrm{C}$, phosphorylation increased until the Gal-3 concentration reached $15 \mu \mathrm{g} / \mathrm{ml}$. Besides, Gefitinib (ZD1839), a novel epidermal growth factor receptor (EGFR) tyrosine kinase inhibitor, could completely inhibit the phosphorylation of ERK1/2 induced by EGF, but could not inhibit the activity induced by Gal-3 (Figure 1D), which further demonstrated that the phosphorylation of ERK1/2 induced by Gal-3 was mediated through different upstream pathways from EGF.

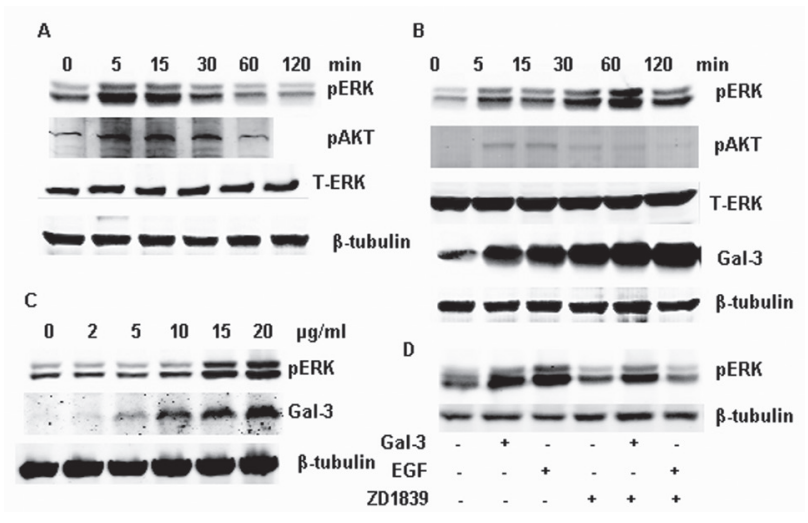

FIGURE 1: Phosphorylation of ERK1/2 induced by EGF and Gal-3 in HeLa cells. HeLa cells were cultured in 6-well cell culture plates, starved by removal of serum for $24 \mathrm{~h}$, and then incubated with EGF (100 ng/ml) and Gal-3 under the stated conditions. After treatment, the cells were collected for western-Blotting using the proper antibodies. A: EGF induced the ERK1/2 phosphorylation. HeLa cells were incubated with EGF $(100 \mathrm{ng} / \mathrm{ml})$ for $0,5,15,30,60,120 \mathrm{~min}$. B: HeLa cells were incubated with Gal-3 $(15 \mu \mathrm{g} / \mathrm{ml})$ for $0,5,15,30,60,120$ min. C: HeLa cells were incubated with $0,2,5,10,15,20 \mu \mathrm{g} /$ $\mathrm{ml} \mathrm{Gal}-3$ for $30 \mathrm{~min}$. D: HeLa cells were incubated with Gal-3 $(15 \mu \mathrm{g} / \mathrm{ml})$ and EGF $(100 \mathrm{ng} / \mathrm{ml})$ in the presence or absence of U0126 and ZD1839 for $30 \mathrm{~min}$, the specific inhibitor of ERK1/2 and EGFR, respectively.
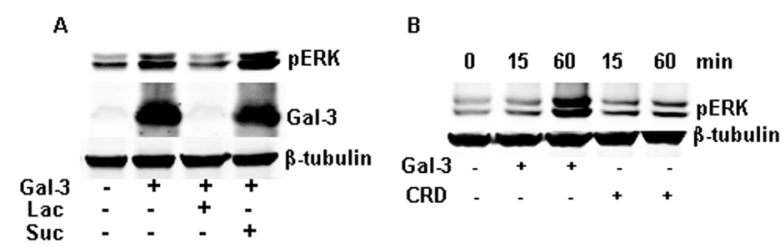

FIGURE 2: Gal-3 induced the phosphorylation of ERK1/2 dependent on its CRD. Starved HeLa cells were incubated with full-length or truncated Gal-3 under the stated condition. The cell lysates were collected for Western-Blotting analysis using the proper antibodies. A: The cells were incubated with Gal-3 $(15 \mu \mathrm{g} / \mathrm{ml})$ in the presence or absence of $50 \mathrm{mM}$ lactose or sucrose. B: The $30 \mu \mathrm{g} / \mathrm{ml} \mathrm{CRD} \mathrm{domain} \mathrm{(including}$ from 111 to 250 animo acids) and full-length Gal-3 $(15 \mu \mathrm{g} / \mathrm{ml})$ were incubated with the cells under the indicated concentration for 15 or 60 minutes. 
Phosphorylation of ERK1/2 induced by Gal-3 is CRD dependent and regulated by the $\mathrm{N}$-terminal domain

Gal-3 is a chimeric gene product composed of a $\mathrm{CRD}$ and N-terminal domain, which were implicated in the carbohydrate-recognition and protein-protein interaction $(1,8,9,20)$. Lactose, a potent antagonist of Gal-3, inhibits the carbohydrate-mediated binding of Gal3 to its ligand(s) [20-23]. As shown in figure 2A, lactose inhibits the phosphorylation of ERK1/2 completely, while sucrose (sugar control) did not. To further make clear the potential roles of the CRD and N-terminal domain in the activation of ERK1/2, we have constructed and expressed truncated proteins and checked their ability to phosphorylate ERK1/2. Compared to the full-length Gal-3, the CRD (111 to 250 amino acids) alone resulted in weak phosphorylation of ERK1/2 even at double the concentration and time (Figure 2B). The N-terminal domain (1 to 108 amino acids) failed to induce the phosphorylation of ERK1/2 (data not shown). Thus, intact Gal-3 is required to activate ERK1/2. Next, we knocked down the expression of Gal-3 in HeLa cells and compared with the negative control siRNA (siCon). Gal3 knockdown diminished the expression of endogenous Gal-3 but did not affect either the basal phosphorylation or the induced phosphorylation of ERK $1 / 2$ by exogenous Gal-3 (Figure 3).

\section{Gal-3 induced ERK1/2 phosphorylation is calcium and Protein Kinase $\mathrm{C}$ dependent}

Calcium ions are secondary signaling molecules for regulating numerous biological processes $[25,26]$. Thus, to study their effect in Gal-3 mediated signaling, we demonstrate in figure 4A, that BAPTM/AM, the cellpermeable calcium chelator, could completely inhibit the phosphorylation of ERK1/2 induced by Gal-3. Calcium

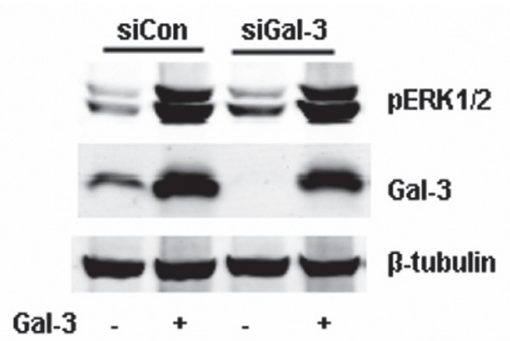

FIGURE 3: Endogenous Gal-3 knockdown did not affect the phosphorylation of ERK1/2 induced by exogenous Gal-3. HeLa cells were treated with the negative control siRNA (siCon) and Gal-3 siRNA (siGal-3) for $24 \mathrm{~h}$, and then starved for $24 \mathrm{~h}$. Gal-3 $(15 \mu \mathrm{g} / \mathrm{ml})$ was added and incubated for $30 \mathrm{~min}$. The cell lysates were collected for Western blotting analysis with the proper antibodies. ions, as an intracellular second messenger, could transfer the signal to the downstream signaling molecules leading to ERK1/2 activation. To further study the downstream signal pathway, we have used specific inhibitors of PLC and PKC kinase, known to be important downstream substrates of calcium ions. As shown in figure 4B, $\mathrm{HMG}$ (1-O-Hexadecyl-2-O-methyl-rac-glycerol), the inhibitor of PKC could decrease the phosphorylation of ERK1/2 induced by Gal-3 and PKC activator, (2-Dioctanoylsn-glycerol), which meant that PKC was involved in the process of ERK1/2 phosphorylation. Conversely, U73122, the phosphoinositide-specific inhibitor of PLC, did not inhibit the phosphorylation of ERK1/2 induced by Gal-3, but it inhibited the phosphorylation induced by m-3M3FBS, a cell-permeable and specific activator of PLC (Figure 4C), suggesting that circulating Gal-3 may affect the intracellular calcium ions levels leading to activation of PKC. This is supported by the finding showing that activated PKC induces the activation of ERK1/2 through Raf-1 [27], and that PKC activates MEK1/2 directly [28]. Cell migration is required for both normal physiological and pathobiological processes [29]. Although, Gal-3 was previously reported to regulate cell migration [30-32], by yet to be detrmined patway Here we report, that circulating Gal-3 mediated HeLa cell

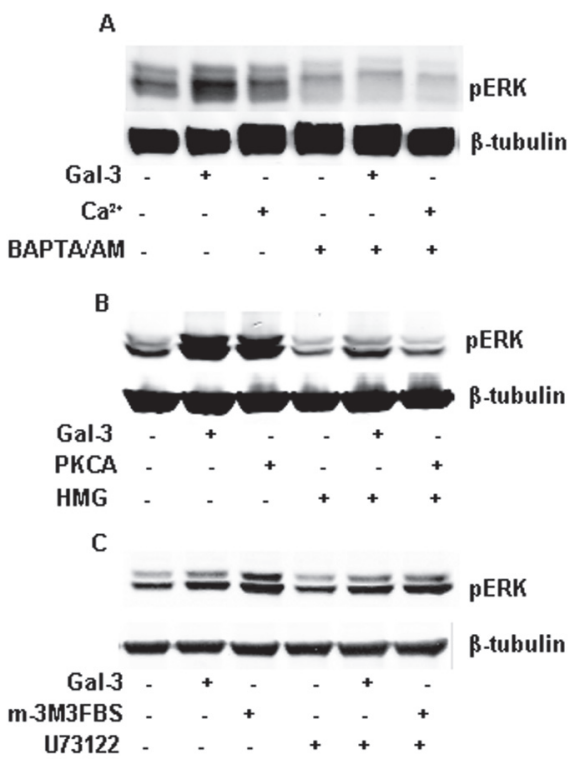

FIGURE 4: Gal-3 activated PKC, not PLC through intracellular calcium ions. Starved HeLa cells were incubated with Gal-3 $(15 \mu / \mathrm{ml})$ or some activators in the presence or absence of some inhibitors in serum-less medium for $15 \mathrm{~min}$. The cell lysates were collected and analyzed by Western Blotting using the proper antibodies. A: HeLa cells were incubated with Gal-3 or calcium ions $\left(\mathrm{Ca}^{2+}\right)$ in the presence or absence of BAPTA/AM as indicated. B: HeLa cells were incubated with Gal-3 or PKCA (150 $\mu \mathrm{M}, 2$-Dioctanoyl-sn-glycerol) in the presence or absence of HMG (150 $\mu \mathrm{M}, 1-\mathrm{O}-\mathrm{Hexadecyl-2-O}$ methyl-rac-glycerol) as indicated. C: HeLa cells were incubated with Gal-3 or m-3M3FBS $(25 \mu \mathrm{M})$ in the presence or absence of $\mathrm{U} 73122(10 \mu \mathrm{M})$ as indicated. 
migration (Figure 5A-5D).

\section{Gal-3 induced ERK1/2 phosphorylation of by is associated with paxillin phosphorylation}

Paxillin, a focal adhesion and signal transduction adaptor protein, is composed of LD motifs, LIM domains, an SH3 domain-binding site and SH2 domainbinding sites, which mediates the protein-protein interaction involved in focal-adhesion dynamics and cell migration [33]. Focal adhesion kinase (FAK) is one of the kinases to phosphorylate paxillin at the sites of tyrosine 31 and tyrosine 118 , which could be phosphorylated by ERK1/2. Thus, Gal-3 enhances the phosphorylation of paxillin at the tyrosine 31 in a time-dependent manner (Figure 6A) and the phosphorylation of paxillin is inhibited by U0126 (Figure 6B) suggesting that ERK1/2 inhibition by U0126 results in the inhibition of paxillin phosphorylation.

\section{DISCUSSION}

Gal-3, a chimeric gene-product containing the NWRG anti-death motif of the Bcl-2 family of proteins plays multiple roles in normal development and cancer progression and metastasis. Secreted Gal-3 exhibits multiple autocrine and paracrine properties $[1,8,9]$, and serves as biomarker to multiple diseases while its exact function and target(s) remains elusive [13-19]. This implies a need for elucidating its function(s) in order to develop a better treatment. Our data identified the pathway induced by exogenous Gal-3 responsible for ERK1/2 phosphorylation, which in turn was required for cell migration. The main signaling mediators in the pathway are summarized: (i) Exogenous Gal-3 (15 $\mu \mathrm{g} /$ $\mathrm{ml}$ ) activated intracellular calcium ions after incubation for $15 \mathrm{~min}$. (ii) Calcium ions activated PKC, but not PLC, because the phosphorylation of ERK1/2 was inhibited by BAPTA/AM, not U73122. (iii) Activated PKC could directly phosphorylate Raf-1 or MEK1/2, which could explain why Gal-3 just induced the phosphorylation of ERK1/2, but not AKT. The activation of AKT mainly resulted from Ras-PI3K signal pathway; however, in our studies the activation of ERK1/2 resulted from PKC. Therefore, Gal-3 activated ERK1/2 selectively bypassed AKT. Using the cell growth assay we show that Gal-3, unlike EGF, did not increase the rate of proliferation of HeLa cells in serum-less medium, raising the possibility that it is associated with the non-activated AKT [34], as

\section{A}

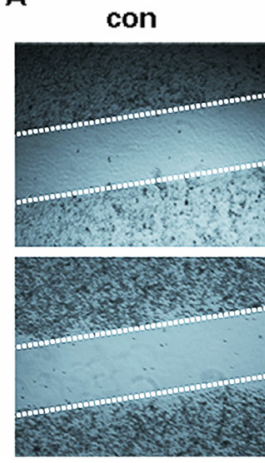

$\mathbf{B}$

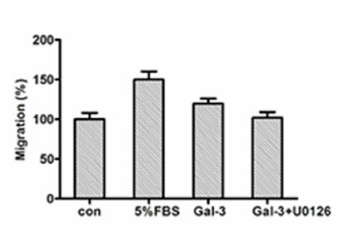

D

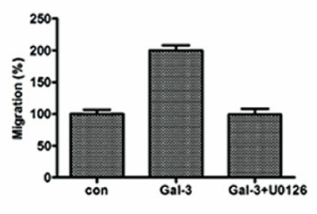

$5 \%$ FBS
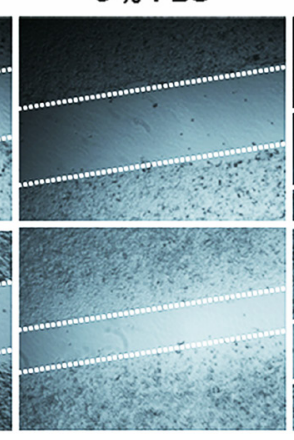

C
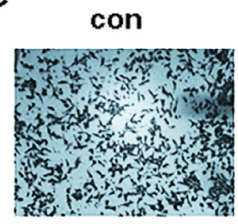

Gal-3

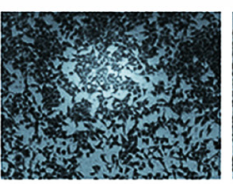

Gal-3 + U0126

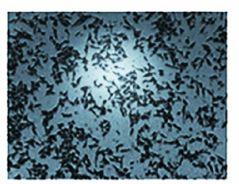

FIGURE 5: ERK1/2 inhibition decreased Gal-3-induced cell migration. A: Starved HeLa cells were incubated with 5\% FBS as the positive control, or Gal-3 in the presence or absence of U0126. The upper panels represent the beginning of cell migration, and the lower panels represent the end after $48 \mathrm{~h}$. The relative cell migration ratio was counted (B). C: Starved HeLa cells were seeded in the cell invasion chamber coated with matrigel with Gal-3 in the presence or absence of U0126 for $24 \mathrm{~h}$. The cells were fixed and stained, and then counted under the microscope (D). 
A
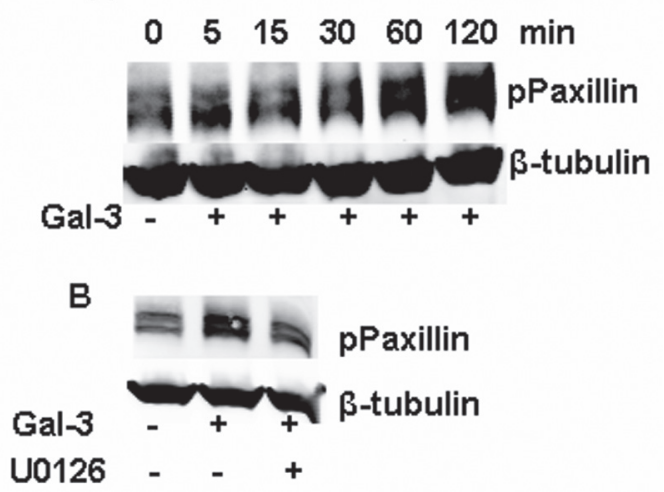

FIGURE 6: ERK1/2 inhibition aborted the phosphorylation of paxillin induced by Gal-3. A: Starved HeLa cells were incubated with Gal-3 $(15 \mu / \mathrm{ml})$ for 0,5 , 15, 30, 60120 min. B: Starved HeLa cells were incubated with Gal-3 $(15 \mu / \mathrm{ml})$ in the presence or absence of U0126 for $60 \mathrm{~min}$. After treatment under the stated conditions, the cell lysates were collected for Western-Blotting analysis.

decrease in cell growth and increase in cell migration protects the cells from apoptosis under starvation [35, 36]. (iv) Activated ERK1/2 induced the phosphorylation of paxillin at tyrosine 31, involved in the cell migration, which means that FAK mediates the phosphorylation of paxillin induced by activated ERK1/2. (v) The activity of Gal-3 to phosphorylate ERK1/2 required both the CRD and N-terminal domain, which play very important roles in regulating its carbohydrate-binding with ligands (2), selfassociation, secretion, and distributions etc. Cell migration is one of the critical steps in both plural physiological and pathological processes. Here we show, for the first time, that calcium ions and ERK1/2 are both central signal molecules involved in Gal-3 mediated cell migrations. ERK1/2 catalyzes the phosphorylation of hundreds of cytoplasmic and nuclear substrates including regulatory molecules and transcription factors [37, 38].

In conclusion, circulated Gal-3, is currently used only as a disease biomarker, however, here we have attempted to decipher part of its molecular mechanism and show that Gal-3 specifically activated ERK/1/2, but not AKT through a calcium-sensitive and PKC-dependent signal pathway. The activated ERK1/2 was required for the induction of cell migration directly or indirectly by phosphorylation of paxillin, an adaptor and scaffold protein associated with focal adhesion and cell motility.

\section{MATERIALS AND METHODS}

\section{Cell lines and regents}

HeLa (Human cervix adenocarcinoma epithelial cell line), was cultured in DMEM with high glucose supplemented with $10 \%$ fetal bovine serum, $100 \mu \mathrm{g} /$ $\mathrm{mL}$ streptomycin, and 100 units $/ \mathrm{mL}$ penicillin and was maintained at $37^{\circ} \mathrm{C}$ in a humidified atmosphere of $95 \%$ air and $5 \% \mathrm{CO}_{2}$. The rat monoclonal antibody against Gal-3 was extracted from the supernatant of hybridoma TIB166 (American Type Culture Collection, Rockville, MD, USA). The monoclonal antibodies against phosphorylated ERK1/2 (E4), total ERK, phosphorylated AKT1/2/3 (Ser473) and the specific siRNA to Gal-3 were purchased from Santa Cruz Biotechnology, Inc. (Santa Cruz, CA.) Rabbit polyclonal antibody against phosphorylated paxillin (pY31) was from BD Biosciences (San Jose, CA). The monoclonal antibody against $\beta$-tubulin was obtained from Sigma Chemical (St. Louis, MO USA). Epidermal growth factor (EGF) was purchase from Cell Signaling Technology (Danvers, MA). U0126, the specific inhibitor of MEK1/MEK2, Wortmannin, a specific covalent inhibitor of phosphoinositide 3-kinases, Gefitinib (ZD1839), a selective EGFR inhibitor 1-O-Hexadecyl2-O-methyl-rac-glycerol, an inhibitor of PKC kinase, and 1,2-Dioctanoyl-sn-glycerol, a cell-permeable PKC activator, were purchased from Cell Signaling Technology. U73122, an inhibitor of phospholipase C, m-3M3FBS, an activator of phospholipase C, and BAPTA/AM, a cell-permeable calcium chelator, were purchased from Calbiochem (Billerica, MA). Lipofectamine RNAiMAX regent was purchased from Invitrogen (Grand Island, NY). Gelcode blue staining regent (24590) and Bio-Rad protein assay kit was both purchased from Bio-Rad Laboratories (Hercules, CA). The lactosyl-sepharose CL 4B was prepared using the lactose and sepharose CL 4B (Sigma) according the protocol published previously [39]. Others were of analytical grade or better.

\section{Preparation of recombinant Gal-3}

The recombinant wide-type Gal-3 and truncated Gal-3mutant were constructed in the plasmid pET-22b (+) and expressed in E.coli BL21(DE3) through inducement by IPTG. The protein were purified using lactosylsepharose CL 4B column according to the protocol reported previously [22]. Finally, the protein concentration and purity were analyzed with Gelcode blue staining regent and Bio-Red protein concentration assay kit. 


\section{Analysis of activation of ERK1/2 and AKT by Gal-3}

The cells were plated in the 6-well plates and cultured overnight. Then, the medium was exchanged with serum-free medium and cultured for another $24 \mathrm{~h}$. The cells were incubated with or without Gal-3 in the presence or absence of inhibitors. Then, the cells were collected for the SDS-PAGE and Western-blotting using the corresponding antibodies.

\section{SDS-PAGE and Western-Blotting}

The cells, plated in the plates, were collected with the cell scraper in RIPA buffer $(20 \mathrm{mmol} / \mathrm{L}$ Tris- $\mathrm{HCl}, \mathrm{pH}$ $7.5,150 \mathrm{mmol} / \mathrm{L} \mathrm{NaCl}, 1 \%$ Triton $\mathrm{NP}-40,0.5 \%$ sodium deoxycholate, and $0.1 \%$ SDS, and adding the $\mathrm{Na}_{3} \mathrm{VO}_{4}$ and PMSF before use) and kept on ice for $30 \mathrm{~min}$. The cell lysate was centrifuged at $14,000 \mathrm{rpm}$ for $15 \mathrm{~min}$ at $4^{\circ} \mathrm{C}$. The supernatant was removed to a new tube and quantitated. Thirty $\mu \mathrm{g}$ of total protein was loaded and separated in $12 \%$ polyacrylamide gel and transferred to PVDF membranes. The membranes were blocked with $0.1 \%$ casein in TBS and checked with primary and secondary antibody. Western blotting was performed with the indicated primary antibodies, followed by secondary antibodies conjugated with Alexa 680 (Molecular Probes) or IRDye 800 (Rockland). Fluorescent signals were detected with an Odyssey infrared imaging system. (Licor Lincoln, NE)

\section{siRNA transfection}

siRNA transfection was performed to knockdown Gal-3 according to the manufacturer's instruction for Lipofectamine RNAiMAX regent. After incubation for $24 \mathrm{~h}$, the cells were starved by replacing the medium with fresh serum-free medium for another $24 \mathrm{~h}$ and then the cells were used to perform other treatments.

\section{Wound-healing Cell migration assay}

Cells were seeded into 24-well tissue culture plate in a density, after 24 hours of growth until confluent. The cells were starved with serum-free medium overnight, and they reached approximate $100 \%$ confluence as a monolayer. Scratching across the surface of the wells with pipet tips created a cross. The lines were photographed on a microscope under the same configuration at the beginning and at the end, and compared the images to quantify the migration rate of the cells.

\section{Cell invasion assay}

HeLa Cells $\left(5 \times 10^{4}\right)$ were suspended in $200 \mu \mathrm{L}$ of serum-free medium after being starved for $24 \mathrm{~h}$, and then seeded onto the upper compartment of an 8.0- $\mu \mathrm{m}$-pore BD Biocoat Matrigel invasion chamber (catalog No. 354480 , BD Biosciences, MA, USA). The lower chamber was filled with normal medium containing $10 \%$ FBS. After incubation for $24 \mathrm{~h}$, the medium in the upper chamber was removed and the filters were fixed with $100 \%$ ethanol for $15 \mathrm{~min}$ and stained with $0.5 \%$ crystal violet for 15 $\min$. The cells remaining on the upper surface of the filter membrane were completely removed by wiping with a cotton swab. The cells that invaded through the membrane were visualized and counted from five randomly selected microscopic fields.

Each experiment was repeated at least three times and representative experiments are presented.

\section{REFERENCES}

1. Dumic J, Dabelic S, Flögel M. Galectin-3: An open-ended story. Biochimica et Biophysica Acta - General Subjects. 2006; 1760: 616-635.

2. Lepur A, Salomonsson E, Nilsson UJ, Leffler H. Ligand induced galectin-3 protein self-association. Journal of Biological Chemistry. 2012 287: 21751-21756.

3. Gong HC, Honjo Y, Nangia-Makker P, Hogan V, Mazurak N, Bresalier RS, Raz A. The NH2 terminus of galectin-3 governs cellular compartmentalization and functions in cancer cells. Cancer Research. 1999; 59: 6239-6245.

4. Haudek KC, Spronk KJ, Voss PG, Patterson RJ, Wang JL, Arnoys EJ. Dynamics of galectin-3 in the nucleus and cytoplasm. Biochimica et Biophysica Acta - General Subjects. 2010; 1800: 181-189.

5. Hughes RC. Secretion of the galectin family of mammalian carbohydrate-binding proteins. Biochimica et Biophysica Acta. 1999; 1473: 14: 172-185.

6. Gabriel A. Rabinovich LGB, Nicola Tinari, Roberto Paganelli, Clara Natoli,, Iacobelli F-TlaS. Galectins and their ligands: amplifiers, silencers or tuners of the inflammatory response? TRENDS in Immunology. 2002; 23: 313-320.

7. Seve AP, Hadj-Sahraoui Y, Felin M, Doyennette-Moyne MA, Aubery M, Hubert J. Evidence that lactose binding to CBP35 disrupts its interaction with CBP70 in isolated HL60 cell nuclei. Experimental Cell Research. 1994; 213: 191-197.

8. Ochieng J, Furtak V, Lukyanov P. Extracellular functions of galectin-3. Glycoconjugate Journal. 2002; 19: 527-535.

9. Liu FT, Patterson RJ, Wang JL. Intracellular functions of galectins. Biochimica et Biophysica Acta - General Subjects. 2002; 1572: 263-273.

10. Sundblad V, Croci DO, Rabinovich GA. Regulated 
expression of galectin-3, a multifunctional glycan-binding protein, in haematopoietic and non-haematopoietic tissues. Histology and Histopathology. 2011; 26: 247-265.

11. Noël JC, Chapron C, Borghese B, Fayt I, Anaf V. Galectin-3 is overexpressed in various forms of endometriosis. Applied Immunohistochemistry and Molecular Morphology. 2011; 19: 253-257.

12. Iurisci I, Tinari N, Natoli C, Angelucci D, Cianchetti E, Iacobelli S. Concentrations of galectin-3 in the sera of normal controls and cancer patients. Clinical Cancer Research. 2000; 6: 1389-1393.

13. Vereecken, P., A. Awada, S. Suciu, G. Castro, R. Morandini, A. Litynska, D. Lienard, K. Ezzedine, G. Ghanem, and M. Heenen. 2009. Evaluation of the prognostic significance of serum galectin-3 in American Joint Committee on Cancer stage III and stage IV melanoma patients. Melanoma Research. 19: 316-320.

14. Balan V, Wang $Y$, Nangia-Makker $P$, Kho D, Bajaj M, Smith D Heilbrun L, Raz A, Heath E. Galectin-3: A possible complementary marker to the PSA blood test. Oncotarget. 2013; 4: 542-549.

15. Wang X, Zhang S, Faliang Lin, Wenzheng Chu and Shouwei Yue. Elevated Galectin-3 Levels in the Serum of Patients With Alzheimer's Disease. American Journal of Alzheimer's Disease \& Other Dementias. 2013; DOI: $10.1177 / 1533317513495107$

16. Lee YJ, Kang SW, Song JK, Park JJ, Bae YD, Lee EY, Lee EB, Song YW. Serum galectin-3 and galectin-3 binding protein levels in Behçet's disease and their association with disease activity. Clinical and Experimental Rheumatology. 2007; 25: S41-S45.

17. Liu GY, Xu Y, Li Y, Wang LH, Liu YJ, Zhu D. Secreted galectin-3 as a possible biomarker for the immunomodulatory potential of human umbilical cord mesenchymal stromal cells. Cytotherapy 2013;15: 12081217.

18. Schmitter D, Cotter G, Voors AA. Clinical use of novel biomarkers in heart failure: towards personalized medicine. Heart Failure Reviews: 2013, DOI 10.1007/s10741-0139396-5.

19. Lee YM, Lee JB. Prognostic value of epidermal growth factor receptor, p53 and galectin-3 expression in papillary thyroid carcinoma. Journal of International Medical Research. 2013; 41: 825-834.

20. Fukumori T, Takenaka Y, Yoshii T, Kim HRC, Hogan V, Inohara H, Kagawa S, Raz A. CD29 and CD7 Mediate Galectin-3-Induced Type II T-Cell Apoptosis. Cancer Research. 2003; 63: 8302-8311.

21. Lepur A, Carlsson MC, Novak R, Dumić J, Nilsson UJ, Leffler H.. Galectin-3 endocytosis by carbohydrate independent and dependent pathways in different macrophage like cell types. Biochimica et Biophysica Acta - General Subjects. 2012, 1820: 804-818.

22. Gao X, Liu D, Fan Y, Li X, Xue H, Ma Y, Zhou Y,
Tai G. The Two Endocytic Pathways Mediated by the Carbohydrate Recognition Domain and Regulated by the Collagen-like Domain of Galectin-3 in Vascular Endothelial Cells. PLoS ONE. 2012; 7: e52430.

23. Schneider D, Greb C, Koch A, Straube T, Elli A, Delacour D, Jacob R. Trafficking of galectin-3 through endosomal organelles of polarized and non-polarized cells. European Journal of Cell Biology. 2010; 89: 788-798.

24. Jo M, Thomas KS, O’Donnell DM, Gonias SL. Epidermal growth factor receptor-dependent and -independent cellsignaling pathways originating from the urokinase receptor. Journal of Biological Chemistry. 2013; 278: 1642-1646.

25. Nowycky MC, Thomas AP. Intracellular calcium signaling. Journal of Cell Science. 2002; 115: 3715-3716.

26. Carafoli E. Calcium signaling: A tale for all seasons. Proceedings of the National Academy of Sciences of the United States of America. 2002; 99: 1115-1122.

27. Kolch W, Heidecker G, Kochs G, Hummel R, Vahidi H, Mischak H, Finkenzeller G, Marme D, Rapp UR. Protein kinase C[alpha] activates RAF-1 by direct phosphorylation. Nature. 1993; 364: 249-252.

28. Wen-Sheng W. Protein kinase $\mathrm{C} \alpha$ trigger Ras and Rafindependent MEK/ERK activation for TPA-induced growth inhibition of human hepatoma cell HepG2. Cancer Letters. 2006; 239: 27-35.

29. Yamaguchi H, Wyckoff J, Condeelis J. Cell migration in tumors. Current Opinion in Cell Biology. 2005; 17: 559564.

30. Kim S, Choi I, Cheong T, Lee S, Lotan R, Park SH, Chun K. Galectin-3 Increases Gastric Cancer Cell Motility by Upregulating Fascin-1 Expression. Gastroenterology. 2010; 138: 1035-1045.

31. Hsu DK, Chernyavsky AI, Chen HY, Yu L, Grando SA, Liu FT. Endogenous galectin-3 is localized in membrane lipid rafts and regulates migration of dendritic cells. Journal of Investigative Dermatology. 2009; 129: 573-583.

32. Hittelet A, Legendre H, Nagy N, Bronckart Y, Pector JC, Salmon I, Yeaton P, Gabius HJ, Kiss R, Camby I. Upregulation of galectins-1 and -3 in human colon cancer and their role in regulating cell migration. International Journal of Cancer. 2003; 103: 370-379.

33. Schaller MD. Paxillin: A focal adhesion-associated adaptor protein. Oncogene. 2011; 20: 6459-6472.

34. Carnero, A. The PKB/AKT pathway in cancer. Current Pharmaceutical Design. 2010; 16: 34-44.

35. Chen H, Zhu G, Li Y, Padia RN, Dong Z, Pan ZK, Liu $K$, Huang S Extracellular signal-regulated kinase signaling pathway regulates breast cancer cell migration by maintaining slug expression. Cancer Research. 2009; 69: 9228-9235.

36. Hu CT, Cheng CC, Pan SM, Wu JR, Wu WS. PKC mediates fluctuant ERK-paxillin signaling for hepatocyte growth factor-induced migration of hepatoma cell HepG2. Cellular Signalling. 2013; 25: 1457-1467. 
37. Novak R, Jacob E, Haimovich J, Avni O, Melamed D. The MAPK/ERK and PI(3)K pathways additively coordinate the transcription of recombination-activating genes in B lineage cells. Journal of Immunology. 2010; 185: 3239-3247.

38. McCubrey JA, Steelman LS, Chappell WH, Abrams SL, Wong EWT, Chang F, Lehmann B, Terrian DM, Milella M, Tafuri A, Stivala F, Libra M, Basecke J, Evangelisti C, Martelli AM, Franklin RA. Roles of the Raf/MEK/ERK pathway in cell growth, malignant transformation and drug resistance. Biochimica et Biophysica Acta - Molecular Cell Research. 2007; 1773: 1263-1284.

39. Levi G, Teichberg VI. Isolation and physicochemical characterization of electrolectin, a beta-D-galactoside binding lectin from the electric organ of Electrophorus electricus. Journal of Biological Chemistry. 1981; 256: $5735-5740$. 